\title{
Higher Educational Level in Patients with Eosinophilic Esophagitis: A Comparative Analysis
}

Authors: René Roth¹, Ekaterina Safroneeva², Catherine Saner Zilian³, Philipp Schreiner ${ }^{1}$, Jean-Benoit Rossel ${ }^{3}$, Matthias Bopp ${ }^{4}$, Thomas Greuter ${ }^{1}$, Michael Scharl ${ }^{1}$, Valérie Pittet ${ }^{3}$, Gerhard Rogler ${ }^{1}$, Alain Schoepfer ${ }^{5}$, Alex Straumann ${ }^{1}$ and Luc Biedermann $^{1}$

1 Department of Gastroenterology, University Hospital Zurich (USZ) and University of Zurich, Zurich, Switzerland

2 Institute of Social and Preventive Medicine (ISPM), University of Bern, Bern, Switzerland

3 Institute of Social and Preventive Medicine (IUMSP), Lausanne University Hospital, Lausanne, Switzerland

4 Epidemiology, Biostatistics and Prevention Institute, University of Zurich, Zurich, Switzerland

5 Division of Gastroenterology and Hepatology, Centre Hospitalier Universitaire Vaudois (CHUV) and University of Lausanne, Lausanne, Switzerland

Corresponding author:

René Roth, Spital Limmattal

Urdorferstrasse 100, 8952 Schlieren, Switzerland rene.roth@spital-limmattal.ch 


\section{Authors contributions}

René Roth ${ }^{1,2,3}$, Ekaterina Safroneeva ${ }^{2,3}$, Catherine Saner Zilian ${ }^{3}$, Philipp Schreiner ${ }^{3}$, Jean-Benoit Rossel ${ }^{2}$, Matthias Bopp ${ }^{2,3}$, Thomas Greuter ${ }^{3}$, Michael Scharl ${ }^{3}$, Valérie Pittet $^{3}$, Gerhard Rogler ${ }^{1,3}$, Alain Schoepfer ${ }^{3}$, Alex Straumann $n^{1,2,3}$ and Luc Biedermann ${ }^{1,2,3}$

1 Conception and design of the study

2 Analysis and interpretation of data

3 Drafting and revising

This manuscript, including related data, figures and tables has not been previously published. This manuscript is not under consideration in another medical journal. 


\section{ABSTRACT}

\section{Background}

Eosinophilic Esophagitis is a chronic-inflammatory gastrointestinal disease with a high prevalence in younger, atopic males. In our clinical practice we observed a striking preponderance of patients having a high educational background. The purposes of this study were, first to assess the level of education of Eosinophilic Esophagitis patients; and second to compare the findings to patients with inflammatory bowel disease, another chronic immune-mediated condition of the gastrointestinal tract, and with the Swiss General Population.

\section{Methods}

Using a questionnaire, we assessed the educational level of adult patients who have attended Swiss Eosinophilic Esophagitis Clinics in the past. Additionally, the educational level of the parents was assessed as well. We calculated the proportions of patients and parents who have obtained a higher educational level. Data from the Swiss Inflammatory Bowel Disease Cohort Study and from the Swiss General Population served as confirmation and as comparison, respectively.

\section{Results}

277 successfully contacted patients (response rate $69.1 \%$; mean age 51.1 years, $73 \%$ male) participated. A significantly higher proportion of surveyed Eosinophilic Esophagitis patients had a high ISCED level $(66.8 \%, p<0.001)$ compared to inflammatory bowel disease patients $(n=2534 ; 34.2 \%, p<0.001)$ and to the Swiss General Population ( $n=6$ '066'907; 30.5\% p<0.001).

\section{Conclusion}


Our analysis confirms the clinical observation that Eosinophilic Esophagitis patients have a significantly higher educational level compared to the general population and to patients with other chronic inflammatory diseases of the gastrointestinal tract. As a limitation, this impressive finding remains on a purely descriptive level. 


\section{INTRODUCTION}

Eosinophilic Esophagitis (EoE) is a rapidly emerging, chronic-inflammatory disease of the esophagus ${ }^{1,2}$. Until recently EoE was considered a rare disease but today it is recognized as one of the leading causes of esophageal dysphagia and food impaction in adults, and of food refusal and failure to thrive in children, respectively $y^{3,4}$.

EoE has a distinct genetic component, illustrated by the marked male predominance with about three out of four patients being male $e^{5-8}$. The significantly increased sibling recurrence-risk of greater than $40 \%$ is an additional manifestation of its genetic component ${ }^{9}$. However, a twin study has demonstrated that environmental components play a more important role in the etiopathogenesis of EoE than genetic factors ${ }^{10}$ as also seen in a geographically uneven distribution with higher rates in western countries ${ }^{2,4}$. As it is widely accepted that EoE is a distinctive type of food hypersensitivity ${ }^{6,11}$, it can be speculated that the geographical patterns are explained by different nutritional habits. Aside from genetics and food, several other factors are involved in the etiopathogenesis of this inflammatory condition, including an altered immune response and environmental factors ${ }^{6,12}$. Some of these suspected environmental factors are discussed in a recent review from Jensen et al. ${ }^{13}$. However, one factor that has not been on the board so far is educational level. Over several years we have observed a striking preponderance of a higher educational background amongst our EoE patients. The purposes of this study are therefore first to confirm our observation by means of a systematic assessment of the educational level of our EoE patients using a questionnaire; and second, to compare the findings with the Swiss General Population (SGP) and with patients with other chronic-inflammatory diseases of the gastrointestinal tract. 


\section{MATERIALS AND METHODS}

\section{Questionnaire on Educational Level of Patients and Parents}

The questions on education had been developed, and previously inquired in the SGP by the Swiss Federal Statistical Office (Schweizerisches Bundesamt für Statistik). A cover letter containing information about the rationale of the survey as well as information about the voluntary and anonymous nature of this project was sent out along with a post-paid envelope and the questionnaire. A reminder-letter was sent one month after the initial letter and data closure was pre-scheduled to be performed one month subsequent to the reminder-letter. Patients under age 25 years were excluded from analysis. Educational level (EL) is classified according to the International Standard Classification of Education (ISCED) on a scale from 0 to 8, higher EL, equivalent to a bachelor's degree or higher encompasses ISCED 6-8. The ISCED classification has been developed by the United Nations Educational, Scientific and Cultural Organization (UNESCO) in the 1970s and reworked into its current form in $2011 .{ }^{14}$ Despite concerns regarding reliability and validity of self-reported income ${ }^{15,16}$, we also inquired income in our questionnaire in one question, as income has been shown to strongly correlate with educational level ${ }^{17,18}$.

\section{EoE Educational-Study Population (EoE-ESP)}

443 adult patients with confirmed diagnosis of EoE according to established criteria $^{19}$ and prior consultation in the outpatient clinics either at the Swiss EoE Clinic, Olten (Switzerland) and the Departments of Gastroenterology and Hepatology of the University Hospital Zurich or Lausanne were invited to participate in a survey focusing on the educational level of patients and their parents. These patients will be referred to as EoE-ESP (EoE-Educational-Study-Population). 


\section{Swiss IBD Cohort (SIBDC)}

The Swiss IBD Cohort (SIBDC) was approved by local authorities and ethics committees and launched in 2006; bringing together information of approximately 3000 IBD patients in Switzerland. Retrospective data were obtained from patient charts since diagnosis and a study nurse or a gastroenterologist who completed the report forms collects clinical data during medical visits at inclusion and annual followup. The form is then entered into the database ${ }^{20}$. Besides specific information about IBD, disease activity and many more, the SIBDC also collects information about educational level of the participants. The following data were obtained from the SIBDC for this study: year of birth, sex, highest level of education.

\section{Swiss General Population (SGP)}

The Swiss Federal Statistical Office has performed a decennial population census since 1850. That census has undergone modernization in 2010. Since then, the census is based on the official and harmonized registers of persons of the Swiss Confederation, the cantons and the communes, providing basic information such as age, sex and nationality, but not occupation or educational level. These data are complemented with the 5-year aggregates 2014-2018 of the Structural Enquiry, a yearly microcensus of at least 200 '000 randomly selected individuals aged $15+$ years $\left(2.7 \%\right.$ of the Swiss general population $\left.{ }^{21}\right)$.

\section{Ethics}

According to our consultation with the local ethics committee, no ethical approval was necessary for the anonymous EoE questionnaire. The SIBDC was 
approved by the ethics committee in 2005 (KEK-ZH 1316) and renewed in 2018 (201802068). No ethics approval was needed for the SGP.

\section{Statistics}

Categorical variables were summarized by frequencies and proportions and weighted to the general population where adequate. Differences in their distribution between EoE-ESP, SIBDC and SGP were analyzed using using chi-squared tests or Fisher's exact test in case of small sample size (i.e. for values $<5$ ). For a more precise subanalysis, we analyzed our patient data according to sex and age in categories of ten years. Furthermore, age standardization was applied where appropriate. Relative risks of suffering from EoE according to educational level were calculated as weighted average in comparison to the SGP. 


\section{RESULTS}

\section{Response Rate and Characteristics of the Study Population (EoE-ESP)}

Overall, 443 questionnaires were sent out. Amongst these, 42 (9.5\%) could not be delivered due to mailing difficulties, mainly lack of correct current address. Two hundred seventy-seven of the successfully contacted patients responded, resulting in a response rate of $69.1 \%$ (277/401). After exclusion of 18 questionnaires due to insufficient or absent completion a total of 259 questionnaires could be included in this analysis (Figure 1).

The majority of the EoE-ESP population was of male sex $(73.4 \%)$ and of Swiss citizenship (94.6\%). Approximately one third $(n=88,34.1 \%)$ of the patients in the EoEESP group has undergone at least one esophageal dilation, among those 46 (52.3\%) even more than one procedure (Table 1).

\section{Educational level of EoE study population (ESP) and comparison to the Swiss general population (SGP)}

In our EoE-ESP patients, 173 out of 259 patients (66.8\%) had a higher EL. A population pyramid of the EoE-ESP participants is shown in Figure 2. The proportion of EoE-ESP patients with higher education is significantly higher $(66.8 \%)$ than in the SGP $(30.5 \% p<0.001)$. Standardizing for age even $72.2 \%$ of male EoE-ESP patients had a tertiary education (SGP: $39.5 \%$ ); $49.4 \%$ of female EoE-ESP patients had tertiary education (SGP: $28.3 \%$ ). Statistical significance holds true in most cases when looking at the individual age-sex categories. Looking at males, subjects of the EoEESP group had a significantly higher educational level compared to the SGP in all age categories while female education in the EoE-ESP was in total significantly higher than 
compared to SGP $(p<0.001)$ yet when looking at the different age categories, only the age category $45-54$ years varied significantly from the SGP ( $p=0.0017)$. Using weighted averages for age classes in relation to the SGP we determined significantly increased relative risk of having EoE not only according to higher vs. non higher educational level overall (RR 3.96, $\mathrm{Cl} 3.06-5.13)$ but also in separate according to sex (Figure 3). Looking at income - an important constitute of socioeconomic status- we observed that the EoE-ESP group had a significantly higher proportion of people in the highest income category with more than every second subject in the EoE-ESP compared to less than every fifth in SGP having an income of more than $104^{\prime} 000$ Swiss francs per year $(54.7 \%$ vs. $17 \%, p<0.0001)$.

\section{Educational level of EoE-Study Population (EoE-ESP) compared to IBD Patients} (SIBDC)

In comparison to EoE, IBD patients - suffering from another immune-mediated chronic inflammatory disease of the luminal gastrointestinal tract - from the Swiss IBD cohort had a significantly lower proportion of subjects with tertiary education $(p<0.001)$. This difference between EoE and IBD patients was observed overall as well as in male $(72.2 \%$ vs. $42.5 \% ; p<0.001)$ and female patients $(49.9 \%$ vs $23.0 \% ; p<0.001)$ separately. When looking at the individual age categories, some did not differ (age 3544 male and female, as well as $65-74 \& 75+$ only female).

Comparing SIBDC patients with the SGP, the overall proportion with tertiary education was similar $(32.7 \%$ vs. $33.7 \%, p=0.56)$. Looking at males and females separately however, there was a significant difference $(42.5 \%$ vs. $39.5 \%, p=0.0078 ; 23 \%$ vs. $28.3 \%, p=0.048$ respectively). Furthermore, apart from the age category $25-34$, no 
female age category from the SIBDC differed significantly from the SGP. Looking at males in the SIBDC, only the age groups from $25-34,35-44 \& 55-64$ differed from the SGP ( $p$ values $<0.001,<0.001$ and 0.044 respectively). Figure 4 depicts the agestandardized percentage of tertiary education among the different populations.

\section{Educational level of Parents of the EoE-Study Population (EoE-ESP)}

Looking at the education of parents of the EoE-ESP we observed, that of the majority the higher educated EoE-ESP derived from a higher educated household (63.2\% in males aged 25-34 years, see Table 2 and Table 3 for details). Paternal education appeared to be linked more strongly to the educational level of the offspring than maternal education. 


\section{DISCUSSION}

In our investigation we found EoE to be strongly linked to a higher educational level. This association was identified comparing a large group of Swiss EoE patients not only with the general population of Switzerland but also a Swiss population of patients suffering from IBD, a chronic immune-mediated luminal inflammatory disease of the gastrointestinal tract, comparable to EoE. This increase in EoE risk in higher educated subjects was observed in male and female patients alike. Moreover, this high educational level was observed consistently throughout most age groups. Therefore, the typical profile of EoE patients - young, male, burdened with atopies and Caucasian - at least in Switzerland - , is to be extended to one additional hallmark: a higher educational level.

The proportion of individuals with tertiary education was significantly higher in the EoE population than in the Swiss general population. Furthermore, our data demonstrate that this educational gap also applies to patients suffering from other chronic inflammatory diseases of the gastrointestinal tract, such as Crohn's Disease or Ulcerative Colitis. While many diseases such as diabetes, obesity and circulatory problems follow a social gradient and are more common in people of lower socioeconomic status, only very few diseases, mostly in the atopic field, follow an inverse social gradient. Therefore, our findings increase the robustness of EoE's linkage to the family of atopic diseases ${ }^{22,23}$. It goes without saying that based on our study design we cannot shed light on the potential pathogenetic connection to explain the association of high educational level and EoE.

One potential explanation for this inverse social gradient is subsumed under the hygiene hypothesis which founds on pathogen exposure - or the relative lack thereof 
in higher socioeconomic living conditions, respectively - during pregnancy and early childhood. According to that theory, exposure to microorganisms early in life exerts a protective influence against sensitization to allergens later on and vice versa an overly hygienic lifestyle would promote atopic diseases ${ }^{24-26}$. This could also explain that the prevalence of EoE in westernized countries is higher than elsewhere.

Moreover, our survey shows in addition that EoE patients have also a larger proportion of well-educated parents. Thus, our findings indicate, that an academic milieu may harbor offsprings' risk for $\mathrm{E}^{27}$. However, based on our data we evidently cannot distinguish whether this association is rather due to selection and the fact, that higher education in offspring is strongly linked to a higher education in at least one parent, different behavior or to environmental factors associated to a higher educational level. Income is amongst the most profoundly defining characteristics of a high socioeconomic status ${ }^{28}$. Furthermore, a higher income has been consistently found to correlate with a higher educational level ${ }^{17,18}$. The significantly higher fraction of higher income in our EoE-patients compared to the SGP reinforces our results and implies that EoE is not only associated to higher education but also higher socioeconomic status overall. As a limitation, self-reported data on income has been linked to questionable reliability and validity ${ }^{15,16,29}$ and thus should be interpreted with caution, also taking into account that we assessed income solely based on a single question and not a validated income questionnaire tool. However, income only represents a subordinated item of our investigation and prior research indicated, that income data founding on a single question may be equally reliable as compared to more sophisticated tools ${ }^{29}$.

This is the first study demonstrating a clear correlation between a high educational level and EoE. Strengths of our study are the number of patients included in the 
survey, which we consider relatively high in relation to the epidemiology of EoE, and the high response rate. The high response rate minimizes risk of selection bias among participants. Nevertheless, our study has some relevant limitations: First, since all the data were collected anonymously, there is no way to trace back to individual answers given and thus providing socially desirable answers by the patients could influence the results. Finally, the biggest limitation of our analysis is its pure observational character. All mechanistical explanations discussed above are therefore hypothetic and can give at most some hints for further research directions.

In summary, our study could clearly demonstrate that EoE, in addition to the already well-known characteristics such as male sex, younger age, Caucasian and history of atopic disease, is consistently associated to a high level of education in both male and female patients and regardless of age. 


\title{
REFERENCES
}

\author{
References
}

1. Arias Á, Lucendo AJ. Incidence and prevalence of eosinophilic oesophagitis increase continiously in adults and children in Central Spain: A 12-year population-based study. Dig Liver Dis 2019;51:55-62.

2. Arias Á, Pérez-Martínez I, Tenías JM, Lucendo AJ. Systematic review with meta-analysis: the incidence and prevalence of eosinophilic oesophagitis in children and adults in population-based studies. Aliment Pharmacol Ther 2016;43:3-15.

3. Biedermann L, Straumann A. Medical and dietary treatments in eosinophilic esophagitis. Curr Opin Pharmacol 2018;43:139-44.

4. Abe Y, Sasaki Y, Yagi M, Yaoita T, Nishise S, Ueno Y. Diagnosis and treatment of eosinophilic esophagitis in clinical practice. Clin J Gastroenterol 2017;10:87-102.

5. Chehade M, Jones SM, Pesek RD, et al. Phenotypic Characterization of Eosinophilic Esophagitis in a Large Multicenter Patient Population from the Consortium for Food Allergy Research. J Allergy Clin Immunol Pract 2018;6:1534-1544.e5.

6. Davis BP, Rothenberg ME. Mechanisms of Disease of Eosinophilic Esophagitis. Annu Rev Pathol 2016;11:365-93.

7. Carr S, Chan ES, Watson W. Eosinophilic esophagitis. Allergy Asthma Clin Immunol 2018;14:58.

8. Blanchard C, Wang N, Stringer KF, et al. Eotaxin-3 and a uniquely conserved geneexpression profile in eosinophilic esophagitis. J Clin Invest 2006;116:536-47.

9. Straumann A, Blanchard C, Radonjic-Hoesli S, et al. A new eosinophilic esophagitis (EoE)like disease without tissue eosinophilia found in EoE families. Allergy 2016;71:889-900.

10. Alexander ES, Martin LJ, Collins $\mathrm{MH}$, et al. Twin and family studies reveal strong environmental and weaker genetic cues explaining heritability of eosinophilic esophagitis. J Allergy Clin Immunol 2014;134:1084-1092.e1.

11. Capucilli P, Cianferoni A, Grundmeier RW, Spergel JM. Comparison of comorbid diagnoses in children with and without eosinophilic esophagitis in a large population. Ann Allergy Asthma Immunol 2018;121:711-6.

12. Chehade M. Eosinophilic esophagitis 25 years after its recognition: Where do we stand? Ann Allergy Asthma Immunol 2018;121:141-2.

13. Jensen ET, Dellon ES. Environmental factors and eosinophilic esophagitis. J Allergy Clin Immunol 2018;142:32-40.

14. international-standard-classification-of-education-isced-2011-en.

15. Kim C, Tamborini CR. Response Error in Earnings: An Analysis of the Survey of Income and Program Participation Matched With Administrative Data. Sociological Methods \& Research 2012;43:39-72.

16. Jeffrey C. Moore, Linda L. Stinson, and Edward J. Welniak, Jr. Income Measurement Error in Surveys: A Review.

17. Psacharopoulos G, Patrinos H. Returns to investment in education: a decennial review of the global literature. Education Economics 2018;26:1-14.

18. Blanden J. Family Income and Educational Attainment: A Review of Approaches and Evidence for Britain. Oxford Review of Economic Policy 2004;20:245-63.

19. Liacouras CA, Furuta GT, Hirano I, et al. Eosinophilic esophagitis: updated consensus recommendations for children and adults. United States, 2011 Jul.

20. Pittet $V$, Juillerat $P$, Mottet $C$, et al. Cohort Profile: The Swiss Inflammatory Bowel Disease Cohort Study (SIBDCS). International Journal of Epidemiology 2010;39:929.

21. Merkmalskatalog, die neue Volkszählung, BFS-Nummer 1132-1101-05, 19.12.2011.

22. McNamara CL, Balaj M, Thomson KH, Eikemo TA, Solheim EF, Bambra C. The socioeconomic distribution of non-communicable diseases in Europe: findings from the European Social Survey (2014) special module on the social determinants of health. Eur J Public Health 2017;27:22-6. 
23. Uphoff E, Cabieses B, Pinart M, Valdés M, Antó JM, Wright J. A systematic review of socioeconomic position in relation to asthma and allergic diseases. Eur Respir J 2015;46:364-74.

24. Ege MJ. The Hygiene Hypothesis in the Age of the Microbiome. Ann Am Thorac Soc 2017;14:S348-S353.

25. Okada H, Kuhn C, Feillet $\mathrm{H}$, Bach J-F. The 'hygiene hypothesis' for autoimmune and allergic diseases: an update. Clin Exp Immunol 2010;160:1-9.

26. van Tilburg Bernardes E, Arrieta M-C. Hygiene Hypothesis in Asthma Development: Is Hygiene to Blame? Arch Med Res 2017;48:717-26.

27. Falcon J. Temporal Trends in Intergenerational Social Mobility in Switzerland: A Cohort Study of Men and Women Born between 1912 and 1974. Swiss Journal of Sociology 2012;38:153-75.

28. Darin-Mattsson A, Fors S, Kåreholt I. Different indicators of socioeconomic status and their relative importance as determinants of health in old age. International Journal for Equity in Health 2017; $16: 173$.

29. John Micklewright, Sylke V. Schnepf. How Reliable are Income Data Collected with a Single Question? 


\section{Figures and Tables}

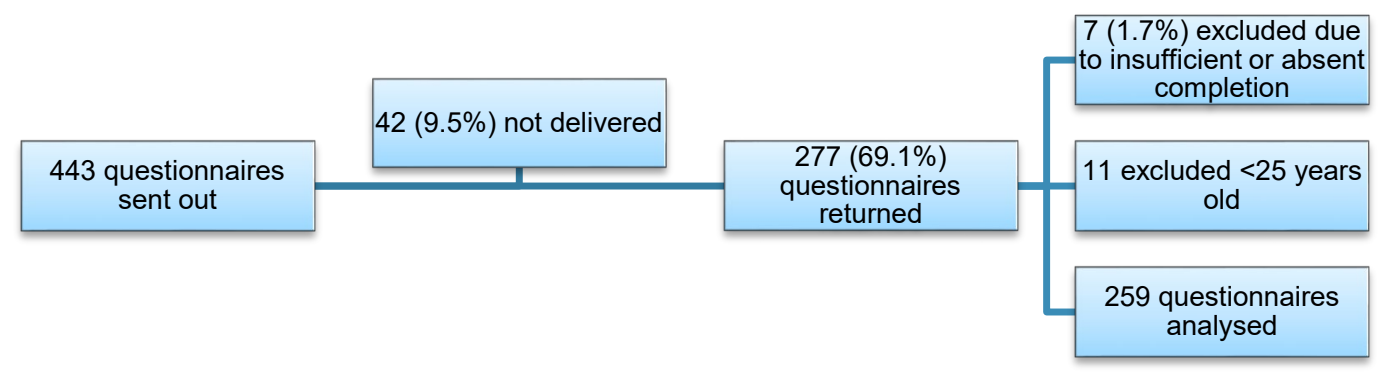

Figure 1: Questionnaire flow chart. The flow chart depicts the number of distributed and returned questionnaires and patients that finally could be analyzed in our study.

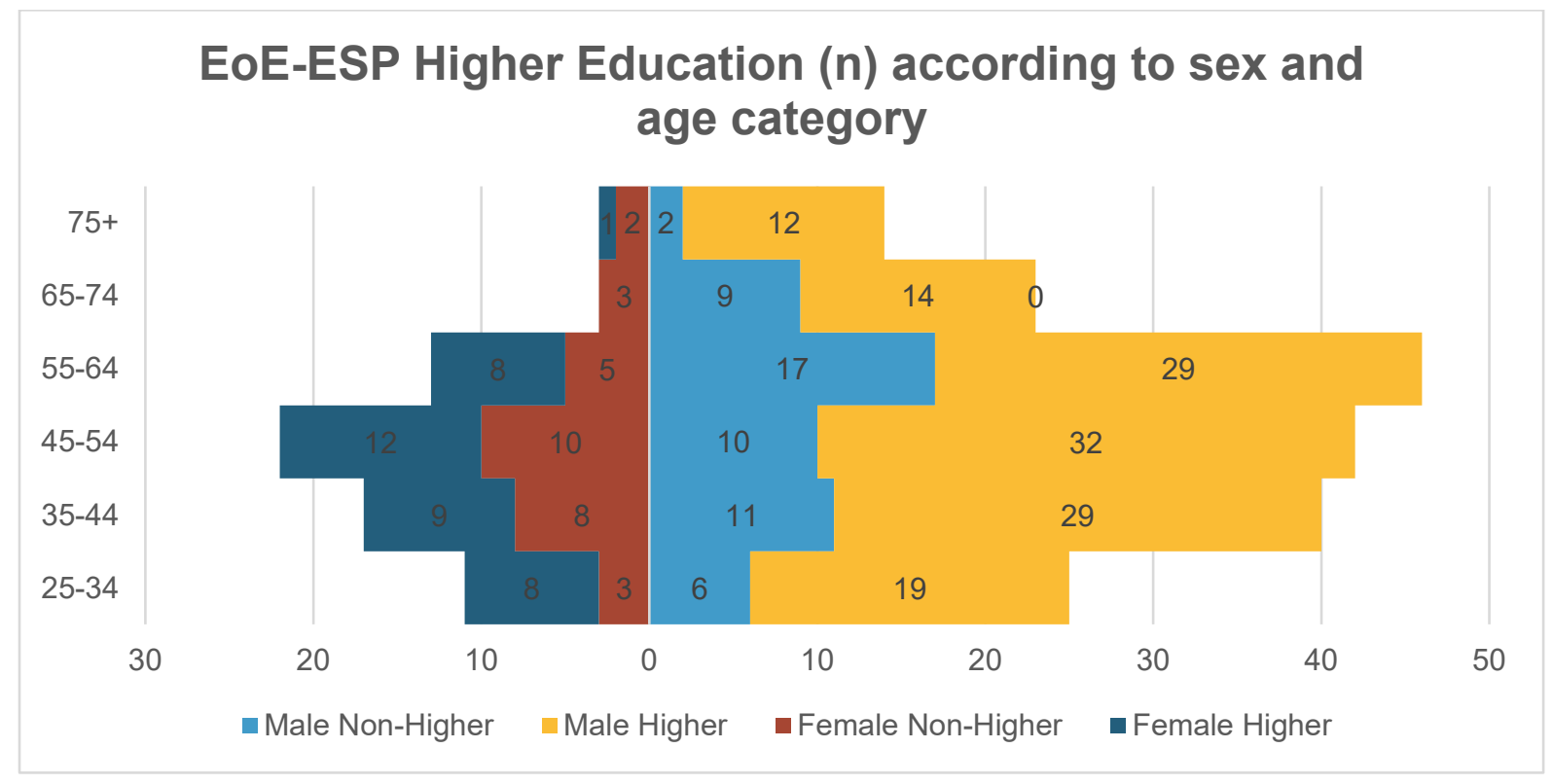

Figure 2: EoE-ESP population pyramid. This population pyramid displays the numbers of males and female according to the age categories. 


\section{Relative Risk of Having EoE According to Educational Level and Sex}

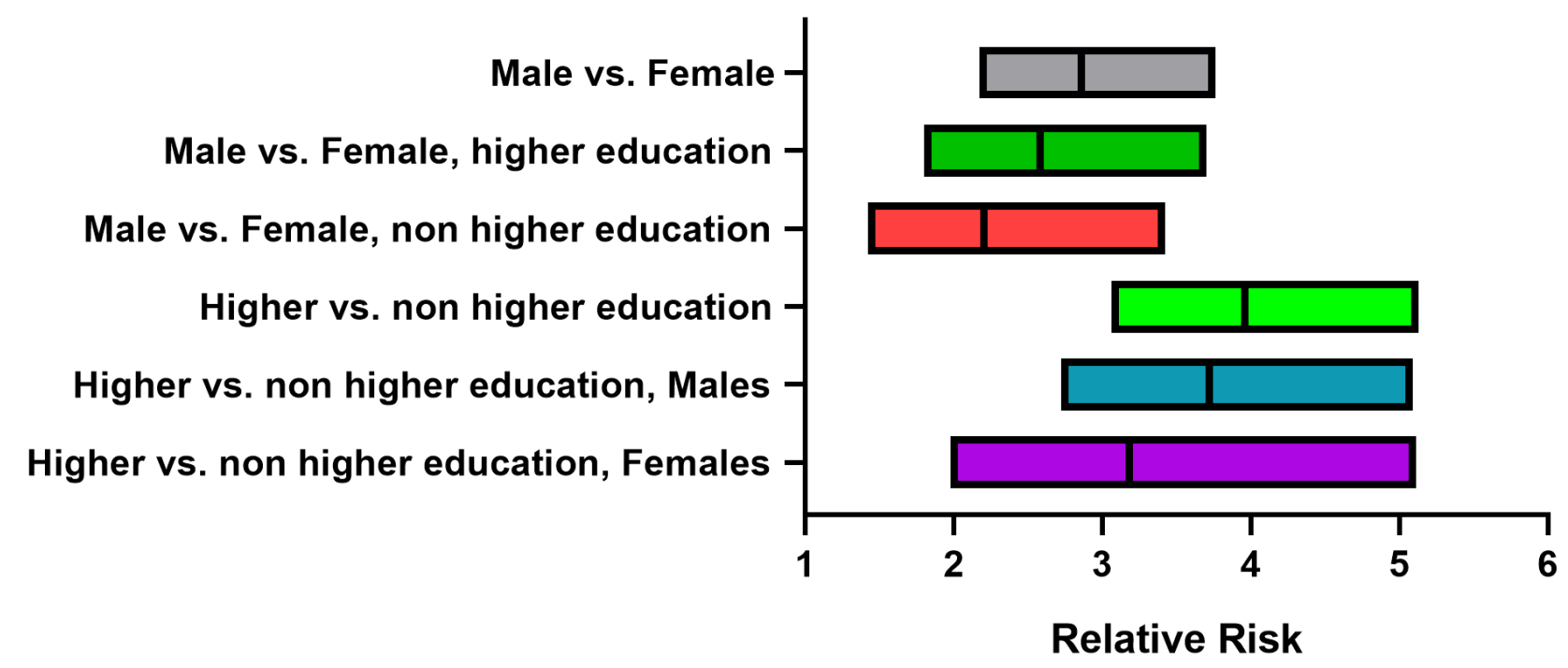

Figure 3 Relative Risk of Having EoE. Bar Chart depicting relative risk (thin black line in the bar's center) with 95\% confidence interval.

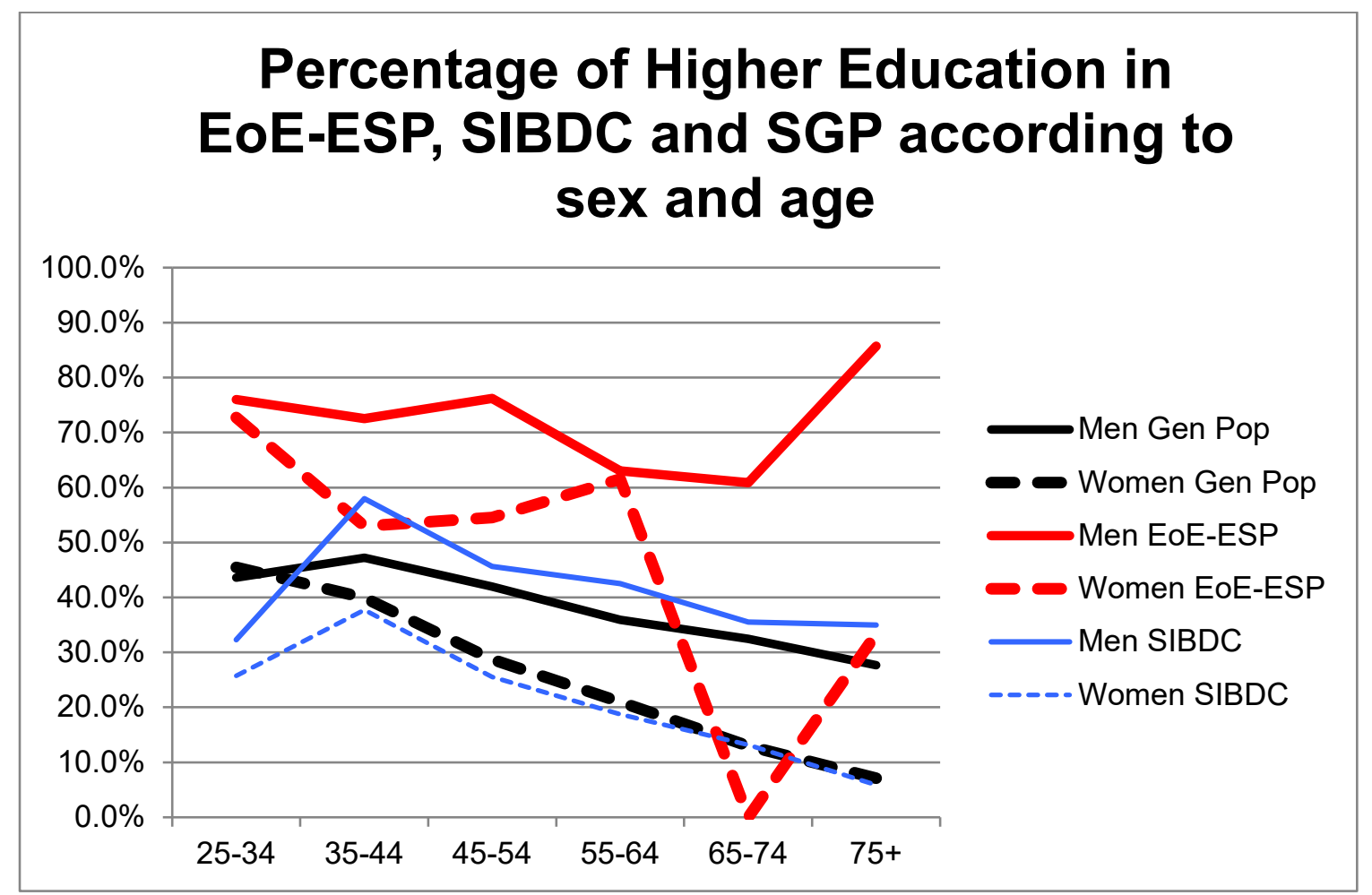

Figure 4 Percentage of Higher Education. This Figure depicts the percentage of higher education amongst the different cohorts stratified by age and sex. Gen Pop equals SGP. 
Table 1: Characteristics of the EoE-ESP study population. The table displays general and disease specific information about the EoE-ESP population.

\begin{tabular}{|c|c|c|}
\hline EoE-ESP & population & n (\%) \\
\hline
\end{tabular}

\begin{tabular}{|c|c|c|c|}
\hline Mean Age (range) & $51.1(25-90)$ & & \\
\hline \multirow[t]{2}{*}{ Sex } & Male & Female & \\
\hline & $190(73.4 \%)$ & $69(26.6 \%)$ & \\
\hline \multirow[t]{2}{*}{ Citizenship } & Swiss & Other & \\
\hline & $245(94.6 \%)$ & $14(5.4 \%)$ & \\
\hline \multirow[t]{2}{*}{ Country of Birth } & Switzerland & Other & \\
\hline & $235(90.7 \%)$ & $24(9.3 \%)$ & \\
\hline \multirow[t]{2}{*}{ Marital Status } & Single & Married & $\begin{array}{l}\text { Widowed, divorced or } \\
\text { living separately }\end{array}$ \\
\hline & $58(22.4 \%)$ & $181(69.9 \%)$ & $20(7.7 \%)$ \\
\hline \multirow[t]{2}{*}{ Place of Living } & Urban & Rural & \\
\hline & $95(37.3 \%)$ & $160(62.7 \%)$ & \\
\hline $\begin{array}{l}\text { Year of first manifestation } \\
\text { (Mean) }\end{array}$ & 2001 & & \\
\hline Year of first Diagnosis (Mean) & 2009 & & \\
\hline Diagnostic delay (mean) & 8 years & & \\
\hline \multirow[t]{2}{*}{ Bolus Impaction } & Yes & No & \\
\hline & $97(37.5 \%)$ & $162(62.5 \%)$ & \\
\hline \multirow[t]{2}{*}{ Need for Dilatation } & No & Once & Multiple Times \\
\hline & $170(65.9 \%)$ & $42(16.3 \%)$ & $46(17.8 \%)$ \\
\hline
\end{tabular}

Table 2 Parental education in higher EoE-ESP. This table displays the proportion of higher educated EoE-ESP patients with higher educated parents. Stratified for age and sex.

\begin{tabular}{rrrrr}
\hline Age & $\begin{array}{l}\text { Male higher with } \\
\text { Father higher }\end{array}$ & $\begin{array}{l}\text { Male higher with } \\
\text { Mother higher }\end{array}$ & $\begin{array}{l}\text { Female higher with } \\
\text { Father higher }\end{array}$ & $\begin{array}{l}\text { Female higher with } \\
\text { Mother higher }\end{array}$ \\
\hline $25-34$ & $63.2 \%$ & $21.1 \%$ & $62.5 \%$ & $50.0 \%$ \\
$35-44$ & $44.8 \%$ & $17.2 \%$ & $44.4 \%$ & $11.1 \%$ \\
$45-54$ & $34.4 \%$ & $15.6 \%$ & $41.7 \%$ & $16.7 \%$ \\
$55-64$ & $27.6 \%$ & $3.4 \%$ & $50.0 \%$ & $12.5 \%$ \\
$65-74$ & $28.6 \%$ & $14.3 \%$ & $0.0 \%$ & $0.0 \%$
\end{tabular}


Table 3 Parental education in overall EoE-ESP. This table displays the proportion of higher educated parents overall in the EoE-ESP. Stratified for age and sex.

\begin{tabular}{ccccc}
\hline Age & $\begin{array}{c}\text { Male total with } \\
\text { Father higher }\end{array}$ & $\begin{array}{c}\text { Male total with } \\
\text { Mother higher }\end{array}$ & $\begin{array}{c}\text { Female total with } \\
\text { Father higher }\end{array}$ & $\begin{array}{c}\text { Female total with } \\
\text { Mother higher }\end{array}$ \\
\hline $25-34$ & $48.0 \%$ & $24.0 \%$ & $54.5 \%$ & $36.4 \%$ \\
$35-44$ & $37.5 \%$ & $12.5 \%$ & $29.4 \%$ & $11.8 \%$ \\
$45-54$ & $28.6 \%$ & $11.9 \%$ & $27.3 \%$ & $9.1 \%$ \\
$55-64$ & $19.6 \%$ & $2.2 \%$ & $38.5 \%$ & $15.4 \%$ \\
$65-74$ & $21.7 \%$ & $8.7 \%$ & $0.0 \%$ & $33.3 \%$ \\
$75+$ & $14.3 \%$ & $7.1 \%$ & $33.3 \%$ & $0.0 \%$ \\
\hline
\end{tabular}




\section{Questionnaire}

Originally sent out in German, translated into English. Please note that the educational terms in questions $12-13 \mathrm{~b}$ have been translated and may therefore be subject to translational vagueness und may further differ in terms of ISCED classification depending on country specific educational systems. (See ISCED classification for details)

1. Your year of birth?

2. Your Sex?

$\square$ female

male

3. Your Citizenship?

Swiss

Other:

Swiss and Other:

4. Your country of birth?

Switzerland

Other:

5. Your marital status?
single
married
widowed
divorced
living separately

6. Your place of living?

State:

/ Zip-code:

7. When in your life did you feel symptoms of the - then possibly not yet diagnosedeosinophilic esophagitis? (year date)

8. When has the eosinophilic esophagitis been diagnosed? (year date)

9. Your place of living when you were diagnosed with eosinophilic esophagitis?

Country: I State: / Zip-code:

10. Did you ever have food stuck that required urgent gastroscopy? No 
11. Did you ever necessitate dilation of your esophagus?

$\square$ No

$\square$ Yes, once.

$\square$ Yes, more than once 
12. Please complete the following

a) all your educations that you have completed

(More than one answer possible)

b) ... please fill into column b) your current education (only one possible).

\begin{tabular}{|c|c|c|}
\hline $\begin{array}{l}\text { a) } \\
\text { Completed } \\
\text { Education }\end{array}$ & $\begin{array}{l}\text { b) } \\
\text { Current } \\
\text { Education }\end{array}$ & \\
\hline$\square$ & $\square$ & None \\
\hline$\square$ & $\square$ & $\begin{array}{l}\text { Mandatory school up to maximum } \\
\text { of } 7 \text { years }\end{array}$ \\
\hline$\square$ & $\square$ & $\begin{array}{l}\text { Mandatory school (incl. Junior high } \\
\text { school) }\end{array}$ \\
\hline$\square$ & $\square$ & $\begin{array}{l}1 \text { year pre-apprenticeship, } 1 \text { year } \\
\text { general education, similar } \\
\text { educations }\end{array}$ \\
\hline$\square$ & $\square$ & $\begin{array}{l}2-3 \text { years diploma middle school, } \\
\text { traffic school, specialized middle } \\
\text { school }\end{array}$ \\
\hline$\square$ & $\square$ & $\begin{array}{l}\text { Vocational } \\
\text { (apprenticeship, 2- 4y vocational } \\
\text { schools, commercial diploma) }\end{array}$ \\
\hline$\square$ & $\square$ & $\begin{array}{l}\text { High School, teacher seminar } \\
\text { (preparatory education for } \\
\text { teachers in kindergarden and } \\
\text { primary school) }\end{array}$ \\
\hline$\square$ & $\square$ & Vocational or specialized maturity \\
\hline$\square$ & $\square$ & $\begin{array}{l}\text { Higher technical or vocational } \\
\text { education with federal diploma }(2 y)\end{array}$ \\
\hline$\square$ & $\square$ & Higher technical school (3y) \\
\hline$\square$ & $\square$ & Bachelors degree or equivalent \\
\hline$\square$ & $\square$ & Masters degree or equivalent \\
\hline$\square$ & $\square$ & Doctorate or higher \\
\hline
\end{tabular}


13a. Please tick all educations, which YOUR MOTHER has completed. (Several answers possible)

\begin{tabular}{ll}
\hline & None \\
\hline & Mandatory school up to maximum of 7 years \\
\hline & Mandatory school (incl. Junior high school) \\
\hline & 1 year pre-apprenticeship, 1 year general education, similar educations \\
\hline & $2-3$ years diploma middle school, traffic school, specialized middle school \\
\hline & Vocational training (apprenticeship, 2- 4y vocational schools, commercial diploma) \\
\hline & High School, teacher seminar (preparatory education for teachers in kindergarden and \\
\hline & primary school) \\
\hline & Vocational or specialized maturity \\
\hline & Higher technical or vocational education with federal diploma (2y) \\
\hline & Higher technical school (3y) \\
\hline & Bachelors degree or equivalent \\
\hline & Masters degree or equivalent \\
\hline & Doctorate or higher \\
\hline & I do not know \\
\hline & None \\
\hline & Mandatory school up to maximum of 7 years \\
\hline & Mandatory school (incl. Junior high school) \\
\hline & 1 year pre-apprenticeship, 1 year general education, similar educations \\
\hline & 2-3 years diploma middle school, traffic school, specialized middle school \\
\hline & Vocational training (apprenticeship, 2- 4y vocational schools, commercial diploma) \\
\hline & High School, teacher seminar (preparatory education for teachers in kindergarden and \\
\hline & primary school) \\
\hline & Vocational or specialized maturity \\
\hline & Higher technical or vocational education with federal diploma (2y) \\
\hline & Higher technical school (3y) \\
\hline & Machelors degree or equivalent \\
\hline & Doctorate or higher \\
\hline & I do not know \\
\hline &
\end{tabular}


13b. Please tick all educations, which YOUR FATHER has completed. (Several answers possible)

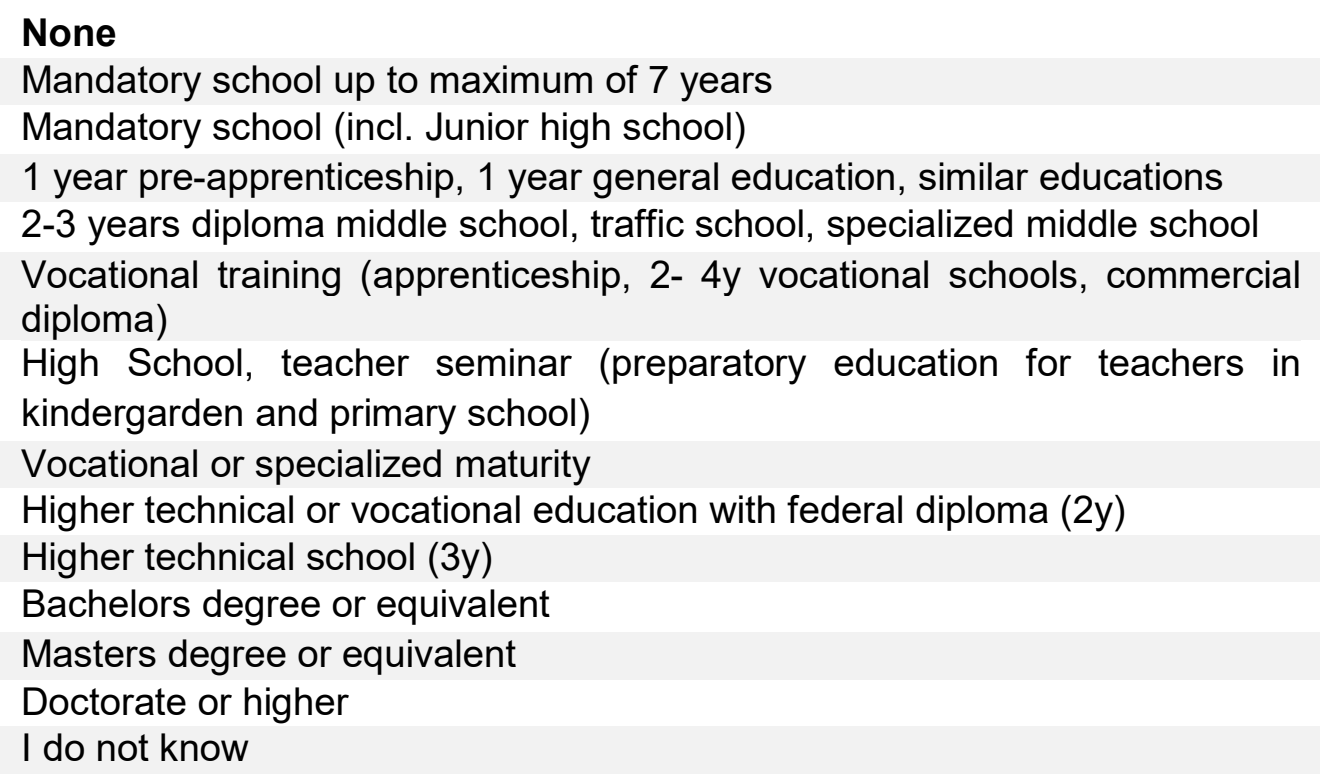


14. Would you be willing to give some information about your current salary?

$\square$ No, despite the anonymous nature of this questionnaire, I do not want to reveal any information about my salary.

$\square$ Yes, my monthly gross salary is:

$$
\begin{aligned}
& \square \leq 4000 \mathrm{CHF} \\
& \square 4000-6000 \mathrm{CHF} \\
& \square 6000-8000 \mathrm{CHF} \\
& \square 8000-10^{\prime} 000 \mathrm{CHF} \\
& \square \geq 10{ }^{\prime} 000 \mathrm{CHF}
\end{aligned}
$$

